\title{
TRABALHO, AGRICULTURA CAMPONESA E PRODUÇÃO DO CONHECIMENTO AGROECOLÓGICO
}

\author{
MÁrcio Gomes da SiLVA \\ Universidade Federal de Viçosa (UFV), Viçosa, Minas Gerais, Brasil
}

\begin{abstract}
Resumo: Este texto tem como objetivo analisar a produção do conhecimento relacionado à agricultura de base agroecológica a partir das contradições históricas do campo brasileiro. Para tanto, são analisadas as mudanças ocorridas no campo, especificamente com a expansão da agricultura capitalista e suas implicações para a agricultura camponesa. Na conformação das relações de trabalho e da relação ser humano-natureza estabelecidas na agricultura camponesa, é que se edificam as condições materiais sob as quais se erguem as bases para a produção do conhecimento agroecológico. A produção do conhecimento agroecológico se dá por meio da agricultura camponesa, do conhecimento tradicional e pela produção da ciência, que se estabelece em relação direta com o conhecimento tradicional.
\end{abstract}

Palavras-chave: Trabalho. Agricultura Camponesa. Agroecologia. Conhecimento tradicional.

\section{INTRODUÇÃO}

Para tratar da temática do trabalho e da produção do conhecimento na agroecologia sob a luz do materialismo histórico é necessário compreender as contradições históricas que compõem o campo brasileiro. Nesse sentido, a agroecologia é vista como o resultado das contradições do modo de produção capitalista de se fazer agricultura e, de forma dialética, produto 
também da resistência histórica de camponeses que não se sujeitam à lógica de reprodução do capital (CALDART, 2016).

A agricultura camponesa se constitui enquanto "[...] alternativa hegemônica do trabalho" (CALDART, 2016, p. 2) por reunir características em seu interior que não se inserem na lógica de reprodução do capital. Essas características referem-se à apropriação dos resultados do trabalho pelos camponeses e às formas diferenciadas de relação com a natureza. As especificidades da agricultura camponesa podem ser sistematizadas em alguns aspectos tais como: a) o objetivo central da produção está relacionada à reprodução social dos camponeses; b) o trabalho e uso da terra é de base familiar; c) o manejo dos agroecossistemas locais específicos de cada região; d) o conhecimento gerado pela forma de produção e manejo tornam-se referências para os próximos ciclos produtivos (CALDART, 2016)

Por outro lado, a forma de agricultura hegemônica constituída pelo modo de produção capitalista é a agricultura industrial, ou agronegócio ${ }^{1}$. Tal forma de se fazer agricultura tem como objetivo principal a subordinação da agricultura à lógica capitalista de reprodução do capital, o que significa uma mudança profunda da lógica camponesa de se fazer agricultura, promovendo uma desconexão entre produção e consumo, além de promover também uma separação entre a produção agrícola e as especificidades dos ecossistemas nos quais a produção é estabelecida (PLOEG, 2008). Portanto, têm-se também modificações na estrutura do trabalho camponês, que pela desconexão e subordinação à lógica da agricultura industrial se torna alienado na medida em que os camponeses passam a adotar os "pacotes tecnológicos", produzidos pela indústria capitalista (CALDART, 2016).

Portanto, à medida que se modificam as relações da agricultura camponesa pela contradição inerente à expansão da agricultura industrial capitalista, modificam-se também as formas de trabalho e de relação com a natureza, e, por conseguinte, a forma de produção de conhecimento. $\mathrm{O}$ objetivo deste texto é analisar a conformação da produção do conhecimento relacionado à agricultura em meio a suas contradições históricas. Portanto, a questão teórica envolvida na pesquisa é analisar os determinantes sociais na forma de se produzir a vida na agricultura camponesa. Esses determinantes ajudam a estabelecer a produção do conhecimento agroecológico e, por conseguinte, um modelo de agricultura, de campo e de sociedade ancorados na agroecologia?

Para tentar responder a essas questões, o texto está organizado em duas partes. Na primeira serão analisadas as mudanças ocorridas no campo, especificamente a partir da expansão da agricultura capitalista. Esse 
tipo de agricultura gerou um conhecimento artificializado e foi difundido por diferentes instituições de ensino e pesquisa, por meio, principalmente, da Revolução Verde ${ }^{2}$. Na segunda parte será analisada a produção do conhecimento ancorada na agricultura camponesa. Na conformação das relações de trabalho e da relação ser humano-natureza estabelecidas nesse tipo de agricultura edificam-se as condições materiais sob as quais se erguem as bases para a produção do conhecimento agroecológico.

A nossa hipótese é que a partir da expansão da agricultura capitalista, marcada historicamente pela modernização da agricultura, constituiu-se uma forma de se fazer agricultura e uma estrutura de produção de conhecimento acerca dos processos produtivos marcados pela artificialização, pelo uso de insumos químicos, mecanização e monoculturas, em contraponto com o trabalho camponês, arraigado na cultura e nos modos de vida da agricultura camponesa, que mobilizam um repertório específico de conhecimento acerca do funcionamento dos ecossistemas. A mudança no trabalho camponês significa, portanto, mudança na forma de apreender a realidade, ou seja, à medida que o capitalismo avança nessas relações, modifica também a estrutura de produção de conhecimento acerca dos processos produtivos no campo.

A MODERNIZAÇÃO DA AGRICULTURA E O CONHECIMENTO APROPRIADO PELO CAPITAL

A modernização da agricultura no Brasil provocou mudanças envolvendo diferentes aspectos como relações de trabalho no campo; padrão tecnológico de produção agrícola; distribuição espacial da produção; formação dos complexos agroindustriais e inserção da agricultura no mercado internacional (ALENTEJANO, 2012).

Esse processo está diretamente relacionado com a industrialização do país, na qual a agricultura passa a desempenhar um papel estratégico de abastecimento de alimentos para os recém-constituídos centros urbanos. Ao mesmo tempo há uma consolidação desse processo transferência de mão de obra da zona rural para a zona urbana, no sentido de abastecer as indústrias; ou seja, a agricultura vista como subsidiária ao setor industrial (ALMEIDA, 1997).

Esse fenômeno ocorreu com intensidade na década de 1960, não só no Brasil, em toda a América Latina por meio da implantação da chamada Revolução Verde, que se baseava no aumento da produtividade agrícola por meio do uso intensivo de insumos químicos, de variedades de sementes de alto rendimento modificadas geneticamente e por meio da irrigação e da mecanização (ALMEIDA, 1997). O processo de modernização da agricultura foi caracterizado por um padrão tecnológico baseado no binômio químico 
mineral-mecanização; crédito rural privilegiando grandes proprietários; consolidação de cadeias agroindustriais vinculadas à montante com a indústria químico-farmacêutica e de bens de capital; aumento da exportação.

Sua implementação se deu com a intervenção direta do Estado, na qual a atuação se deu no sentido de internacionalização da produção de maquinas e insumos para o setor agrícola, a criação de um sistema de pesquisa e extensão da difusão de técnicas de produção vinculadas diretamente ao setor industrial e as condições para o financiamento dos "pacotes tecnológicos" (ALENTEJANO, 2012).

As consequências desse processo para a agricultura camponesa foram diversas. No âmbito das relações de trabalho houve um avanço do trabalho assalariado, em suas mais diversas manifestações, tais como trabalho temporário, sazonal, enfim, consequências da penetração do capitalismo nas relações produtivas no campo, submetendo a produção e o trabalho ao capital, o que resultou em uma subordinação da agricultura aos "Impérios Agroalimentares" (PLOEG, 2008).

Numa perspectiva histórica, o modelo de agricultura preconizado e difundido pela modernização da agricultura capitalista é muito recente. A apropriação e o domínio dos ecossistemas (e da agricultura) pelo ser humano podem ser datados. Ao se referir à agricultura, essa apropriação nos remete a dez mil anos, data do registro do surgimento da agricultura. A partir desse momento, o ser humano desenvolveu a habilidade, ou melhor, o conhecimento que lhe permitiu aprender o domínio da domesticação dos animais e o cultivo das espécies de plantas utilizadas para alimentação. Nessa perspectiva de agricultura, a base produtiva se dava por meio de pequena escala, com um alto nível de diversidade (biodiversidade) e produtividade ecológica. Nesse contexto, o trabalho é marcado por técnicas de manejo das paisagens que garantiam a reprodução da própria unidade produtiva. Para garantia da subsistência apoiado no trabalho, eram mobilizados trabalho eram mobilizados um repertório de conhecimento ecológico localizado, coletivo e holístico acerca dos processos de produção, que se configuravam por estratégias de uso múltiplos dos recursos naturais. A aprendizagem se dava por meio do modo como se dava a organização da sociedade, ou seja, por meio do trabalho, coletivo, compartilhado juntamente com os meios de produção (TOLEDO; BARRERA-BASSOLS, 2015).

Esse modo de apropriação do ecossistema, tradicional ou camponês foi modificado radicalmente há cerca de 200 anos, como expressão e resultado da revolução industrial e cientifica. Essa mudança para um modo agroindustrial não significou apenas o aumento da produção de excedente, mas diversos impactos sociais, econômicos, culturais e ecológicos. Tais 
impactos referem-se à expulsão de milhares de populações tradicionais, à concentração da posse da terra, à desigualdade econômica e à destruição das culturas e, com elas, todo um repertório de conhecimento utilizado na apropriação dos ecossistemas. De acordo com Toledo e Barrera Bassols (2015, p. 89):

Tal mudança obedeceu à lógica de expansão do capitalismo em escala mundial, que exigia a integração das áreas rurais a economia de mercado, a substituição do trabalho pelo capital e o aumento da produtividade, visando abastecer não só uma crescente população urbana, mas também uma nova indústria em plena fase de ascensão (TOLEDO; BARRERA BASSOLS,2015, p. 89).

Portanto, à medida que o capitalismo se efetiva e'integra' a agricultura no processo de reprodução do capital, tanto as relações sociais de produção se modificam, quanto à estrutura do conhecimento mobilizado para manejo dos ecossistemas também se modifica. Esse conhecimento, ancorado nos saberes tradicionais, na cultura e na forma como se organizava o trabalho no manejo das paisagens se institucionaliza e se vincula diretamente a expansão do capitalismo no campo. De acordo com Toledo e Barrera-Bassols (2015, p. 34))

[...] as formas como os seres humanos têm conseguido se apropriar com sucesso dos recursos da natureza ao longo do tempo estão sujeitas a uma enorme pressão, exercida por diversos fatores e forças [...] trata-se de um conflito nodal entre as formas agroindustriais e as formas tradicionais de produção (TOLEDO; BARRERA BASSOLS, 2015, p. 34).

No caso do Brasil, essa institucionalização do conhecimento (tido como único válido) acerca da agricultura, está intimamente ligada ao surgimento das Ciências Agrárias, na década de 1920. Coelho (2014), ao descrever esse aparecimento, apresenta duas etapas da institucionalização. A primeira definida como ciência-experiência "[...] aproxima-se da vida cotidiana de quem trabalha no campo, da forma comum da produção agrícola ou pecuária" (COELHO, 2014, p. 40). A etapa da ciência experiência ainda se apropria ou leva em consideração um tipo de saber do camponês na estruturação dos seus resultados que, em certa medida, ainda são compartilhados. A segunda, instituída a partir da década de 1950, período em que se intensifica a industrialização e a modernização da agricultura capitalista, é denominada de ciência experimento. Essa forma de se fazer pesquisa "[...] gera uma ciência que se faz em um ambiente artificialmente construído para controle de resultados [...] e viabiliza a transformação desse conhecimento em mercadoria" (COELHO, 2014, p. 54). Portanto, tem-se por meio da institucionalização da produção de conhecimento a apropriação do 
capital não apenas dos meios de produção, mas da tecnologia gerada por esse modelo de agricultura.

Nesse sentido, estabelece-se uma relação entre instituições de pesquisa, vinculadas diretamente a empresas produtoras de conhecimento e ao capital financeiro (por meio de créditos e financiamentos para implantação desse conhecimento na forma de pacotes tecnológicos). O conhecimento tradicional, acumulado por mais de dez mil anos desde o surgimento da agricultura passa a ser tido como inválido, por não promover como resultado a produção de mercadoria. Ao mesmo tempo, cria-se uma estrutura de produção do conhecimento (que possui outras bases), agora vinculada diretamente às empresas produtoras que a elaboram na lógica do capital. As bases anteriores passam a ser negadas. Ao que se refere à construção do conhecimento tradicional, ou o saber do camponês, Iturra (1993 apud TOLEDO; BARRERA-BASSOLS, 2015, p. 93) afirma que:

[...] o saber do camponês é obtido através da relação heterogênea entre grupo doméstico e grupo de trabalho, seja em uma comunidade ou em instâncias superiores. O conhecimento sobre o sistema de trabalho, a epistemologia, é resultado dessa interação em que a lógica indutiva é aprendida na medida em que se vê fazer e se escuta, para depois poder dizer, explicar e devolver o conhecimento ao longo das relações de parentesco e vizinhança.

Ou seja, a expansão capitalista campo, o campo ao mesmo tempo em que gera a apropriação do conhecimento pelo capital, na sua institucionalização e vínculo direto da produção de mercadorias, na forma de tecnologias e técnicas de manejo, também cria modificações na estrutura do trabalho, que passa a ser assalariado, alienado e não se configura enquanto um processo de formação humana em seu sentido ontológico, mas como um mero processo de reprodução do capital.

\section{AGRICULTURA CAMPONESA, CONHECIMENTO TRADICIONAL E A PRODUÇÃO DO CONHECIMENTO AGROECOLÓGICO}

Apesar da modernização da agricultura ter estabelecido um modelo de agricultura hegemônico em relação à agricultura camponesa, vinculado diretamente ao mercado capitalista e com as seguintes características: especializada, produtora de monocultura, mecanizada e estruturada em latifúndio, e o trabalho tornando-se assalariado; ainda permanecem formas de agricultura baseadas em racionalidades que se utilizam de conhecimentos tradicionais, definida por Ploeg (2008), como agricultura camponesa. Esse tipo de agricultura, na visão do autor, está fundado principalmente em: a) uma base 
de recursos limitada, o que leva ao estabelecimento de diferentes estratégias por parte dos camponeses para se chegar a melhores resultados a partir dos recursos disponíveis; $b$ ) o trabalho é a centralidade em detrimento aos objetos do trabalho; c) os recursos e materiais são de posse dos que estão diretamente relacionados aos processos de trabalho; d) a produção é relativamente autônoma, pois permite não apenas a produção de mercadorias, mas a própria manutenção da unidade produtiva (PLOEG, 2008).

Por possuir essas características, principalmente em relação ao trabalho, o conhecimento produzido na agricultura familiar camponesa permite estabelecer um vínculo do trabalho enquanto um princípio educativo, no qual por meio da apropriação dos ecossistemas se produz um conhecimento onde se estabelece as bases científicas e empíricas para produção da agroecologia.

Adotamos o conceito de agroecologia como ciência, prática e movimento (Wezell et al., 2009). Como ciência, a agroecologia se caracteriza por ser multidisciplinar, aportando bases do novo paradigma científico, que procura ser integrador, sistêmico. É a partir do diálogo entre cientistas e camponeses, na diversidade de conhecimentos e de técnicas desenvolvidas na agricultura camponesa, que se desenvolveu a abordagem da agroecologia enquanto ciência (CALDART, 2016). Como prática, a agroecologia resgata e ressignifica práticas tradicionais de manejo dos agrossistemas com uso de recursos locais (recursos biológicos, naturais e também conhecimentos) que promovem autonomia (PLOEG, 2008). Como movimento, a agroecologia se vincula a luta pela construção da agricultura camponesa no século XXI na qual abarca a socialização da propriedade da terra (e a reforma agrária popular), a diversidade cultural dos povos do campo, e as diferentes formas de trabalho camponês (CALDART, 2016).

A partir dessa definição é possível identificar elementos relacionados diretamente à produção do conhecimento na agroecologia. Um primeiro aspecto se refere ao conhecimento tradicional. Não se trata de "transpor" conhecimentos tradicionais aos contextos atuais da agricultura, mas estabelecer uma reconexão com as formas tradicionais de se fazer agricultura, especificamente da agricultura camponesa, alicerçado no tipo de trabalho estabelecido na relação com os recursos locais, de forma que tanto o trabalho quanto o conhecimento sejam compartilhados. Isso implica em dois processos distintos: o primeiro refere-se ao compartilhamento comunitário, de práticas e técnicas de manejo ancoradas em saberes ecológicos fundados na cultura e modo de vida camponês. $O$ segundo refere-se às mediações estabelecidas por instituições de pesquisa e agências de Assistência Técnica e Extensão Rural (ATER) que devem incorporar métodos participativos de construção 
do conhecimento, voltados para conhecimentos locais e, ao mesmo tempo, sistematizados em conhecimentos científicos. É possível sintetizar a produção do conhecimento na agroecologia como base nos seguintes aspectos: a) organização das ações a partir das questões colocadas pelos cotidianos das famílias; b) valorização das iniciativas locais das famílias e às formas de proximidade e trabalho coletivo visando otimizar o uso dos recursos locais voltados para busca de autonomia; c) o desenvolvimento de ações de forma a valorizar as relações pré-existentes nas comunidades (PETERSEN; ALMEIDA, 2006).

A mediação da produção do conhecimento agroecológico, portanto, acontece por meio da agricultura camponesa, na qual se estabelece práticas contra-hegemônicas de se fazer agricultura, em detrimento ao modelo de agricultura capitalista.

\section{CONSIDERAÇÕES FINAIS}

À medida que se modificam as relações da agricultura camponesa pela contradição inerente à expansão da agricultura industrial capitalista, alteram-se também as formas de trabalho e de relação com a natureza, e, por conseguinte, a forma de produção do conhecimento. A expansão capitalista para o campo ao mesmo tempo em que gera a apropriação do conhecimento pelo capital, na sua institucionalização e vínculo direto a produção de mercadorias, na forma de tecnologias e técnicas de manejo, também cria modificações na estrutura do trabalho, que passa a ser assalariado, alienado. Portanto, a partir dessa forma de agricultura capitalista não é possível se edificar a produção de conhecimento agroecológico.

A produção do conhecimento agroecológico, portanto, só é possível na agricultura camponesa, no qual o trabalho é marcado por técnicas de manejo das paisagens que garantem a reprodução da própria unidade produtiva. Portanto, podemos identificar os determinantes para a produção do conhecimento agroecológico fundamentado em alguns aspectos da agricultura camponesa. Um aspecto refere-se ao conhecimento tradicional. A partir do conhecimento tradicional é possível estabelecer uma reconexão com as formas tradicionais de se fazer agricultura, de uso dos recursos locais, de forma que tanto o trabalho quanto o conhecimento sejam compartilhados.

Outro aspecto se dá pelas mediações estabelecidas por instituições de pesquisa e agencias de Assistência Técnica e Extensão Rural - ATER, que devem incorporar métodos participativos de construção do conhecimento, voltados para os conhecimentos locais. 


\section{LABOR, CAMPONESE AGRICULTURE AND PRODUCTION OF AGROECOLOGICAL KNOWLEDGE}

ABstRACT: This text aims to analyze the production of knowledge related to agroecology based on the historical contradictions of the Brazilian field. To do so, we analyze the changes that have taken place in the countryside, specifically with the expansion of capitalist agriculture and its implications for peasant agriculture. In the conformation of the labor relations and human - nature relationship established in peasant agriculture, the material conditions under which the bases for the production of agro-ecological knowledge are built. The production of agroecological knowledge occurs through peasant agriculture, traditional knowledge and the production of science, which establishes itself in direct relation with traditional knowledge.

KEYWORDs: Labor. Peasant Agriculture. Agroecology. Traditional knowledge.

\section{TRABAJO, AGRICULTURA CAMPESINA Y PRODUCCIÓN DE CONOCIMIENTO AGROECOLÓGICO}

RESUMEN: Este texto tiene como objetivo analizar la producción de conocimiento relacionado a la agricultura de base agroecológica a partir de las contradicciones históricas rurales de Brasil. Para ello, se analizan los cambios ocurridos en la zona rural, específicamente con la expansión de la agricultura capitalista y sus efectos en la agricultura campesina. En la formación de las relaciones de trabajo y de la relación ser humano-naturaleza, establecidas en la agricultura campesina es que se edifican las condiciones materiales bajo las cuales se erigen las bases para la producción de conocimiento agroecológico. La producción de conocimiento agroecológico se da por medio de la agricultura campesina, del conocimiento tradicional y por la producción de la ciencia, que se establece en relación directa con el conocimiento tradicional.

Palabras-Clave:Trabajo. Agricultura campesina. Agroecología. Conocimiento tradicional.

\section{NOTAS}

1 Agronegócio é o termo utilizado inicialmente para definição de agricultura de alta tecnologia. Entretanto, atualmente a definição tem um caráter e simbologia política, que ao ser utilizado no âmbito dos movimentos sociais do campo, especificamente o Movimento dos Trabalhadores Rurais Sem Terra (MST) significa uma crítica à con- 
centração fundiária e a matriz produtiva da agricultura industrial capitalista (LEITE, S.P. MEDEIROS, L.S, 2012).

2 "[...] a Revolução Verde foi concebida como um pacote tecnológico - insumos químicos, sementes de laboratório, irrigação, mecanização, grandes extensões de terra - conjugado ao difusionismo tecnológico, bem como uma base ideológica de valorização do progresso. Esse processo vinha sendo gestado desde o século XIX, e, no século XX, passou a se caracterizar como uma ruptura com a história da agricultura" (PEREIRA, M.C.B., 2012, p.685).

\section{REFERÊNCIAS}

ALENTEJANO, P. Modernização da Agricultura. In: CALDART, R.; PEREIRA, I.B.; ALENTEJANO, P.; FRIGOTTO, G. (Org.). Dicionário da Educação do Campo. Expressão Popular. Rio de Janeiro/São Paulo: Expressão popular, 2012.

ALMEIDA, J. Da ideologia do Progresso à ideia do desenvolvimento (rural) sustentável. In: ALMEIDA, J.; NAVARRO, Z. (Org.). Reconstruindo a agricultura: idéias e ideais na perspectiva de um desenvolvimento rural sustentável. Porto Alegre: Editora da Universidade, UFRGS, 1997.

CALDART, R. Trabalho, agroecologia e educação politécnica nas escolas do campo In: PIRES, J. H.; NOVAES, H. T.; MAZIN, Â.; LOPES, J. (Org.). Questão Agrária, Cooperação e Agroecologia. São Paulo: Outras Expressões, 2016. v. III.

COELHO, France Maria Gontijo. A arte das orientações técnicas no campo: concepções e métodos. 2. ed. Viçosa, MG: Suprema, 2014.

ITURRA, R. Letrados y campesinos: el método experimental en antropología económica. In: GUZMAN, E. S. (Ed.). Ecología, Campesinato y Historia. España: Las Ediciones de La Piqueta, 1993. p. 131-152.

LEITE, S.P., MEDEIROS, L.S. Agronegócio. In: CALDART, R.; PEREIRA, I. B.; ALENTEJANO, P.; FRIGOTTO, G. (Org.). Dicionário da Educação do Campo. Rio de Janeiro/São Paulo: Expressão Popular. 2012.

PEREIRA, M. C. B. Revolução Verde. In: CALDART, R.; PEREIRA, I. B.; ALENTEJANO, P; FRIGOTTO, G. (Org.). Dicionário da Educação do Campo. Rio de Janeiro/São Paulo: Expressão Popular, 2012.

PETERSEN, P.; ALMEIDA, S. G. de. Rincões transformadores: trajetória e desafios do movimento agroecológico brasileiro: uma perspectiva a partir da Rede PTA. ASPTA, Rio de Janeiro, 2006. Mimeografado.

PLOEG, J. D. Camponeses e impérios alimentares: lutas por autonomia e sustentabilidade na era da globalização. Tradução Rita Pereira. Porto Alegre: Editora da UFRGS, 2008 
TOLEDO, V.; BARRERA-BASSOLS, N. A memória biocultural: a importância ecológica das sabedorias tradicionais. 1. ed. , São Paulo: Expressão Popular, 2015.

WEZELL, A. et al. Agroecology as a science, a movement and a practice. A review. Agronomy for Sustainable. Development, v. 29, n. 4, 2009. Disponível em: $<$ https://hal. inria.fr/file/index/docid/886499/filename/hal-00886499.pdf>. Acesso em: 3 nov. 2017.

MÁrcio Gomes da Silva: Professor do Departamento de Educação da Universidade Federal de Viçosa. Possui graduação em Gestão de Cooperativas e Mestrado em Extensão Rural pela Universidade Federal de Viçosa. Doutorando no Programa de Pós Graduação em Educação na Universidade Federal Fluminense, na linha Trabalho - Educação.

E-mail: marcio.somes@ufv.br 